\title{
Novel concept using a plastic stent for endoscopic ultrasound-guided hepatico- gastrostomy adjusting the length according to the patient's anatomy
}

Recently, the usefulness of plastic stents for creation of an endoscopic ultrasound-guided hepaticogastrostomy (EUS-HGS) was reported [1 - 3]. Re-intervention using a plastic stent is easy owing to the ability to remove it, which may be difficult with a metal stent $[4,5]$. However, as there are few different types of plastic stent dedicated to creation of an EUS-HGS, in some patients it may be difficult to insert the plastic stent in a proper position.

A 72-year-old man who underwent subtotal gastrectomy with Roux-en-Y anastomosis presented with obstructive jaundice due to recurrence of gastric cancer; he therefore underwent EUS-HGS. In this case, it was difficult to secure a puncture route because of the postoperative anastomosis, so puncture was attempted from the esophagus. After antegrade stenting had been performed, an 8-Fr single-pigtail plastic stent was placed with its proximal tip in the esophagus. The length of plastic stent was not sufficient to move the tip to the stomach ( Fig. 1). Because biliary esophagitis occurred ( $\triangleright$ Fig.2), re-intervention was performed.

After guidewire placement through the fistula and removal of the plastic stent, the required length to place the tip in the stomach, as measured from the fluoroscopic image, was $25 \mathrm{~cm}$ ( $\mathbf{F i g . 3}$ ). In order to prepare a plastic stent of sufficient length, a 7.5-Fr endoscopic nasobiliary drainage (ENBD) tube (Boston Scientific, USA) was cut to $25 \mathrm{~cm}$ and side holes were added ( $\triangleright$ Fig. 4 ). With the remaining ENBD tube being used as a pusher catheter, the long plastic stent was released into the esophagus. The tip was then guided into the stomach with grasping forceps and was successfully placed as planned ( Fig.5). Subsequently, the patient's jaundice and esophagitis both improved.

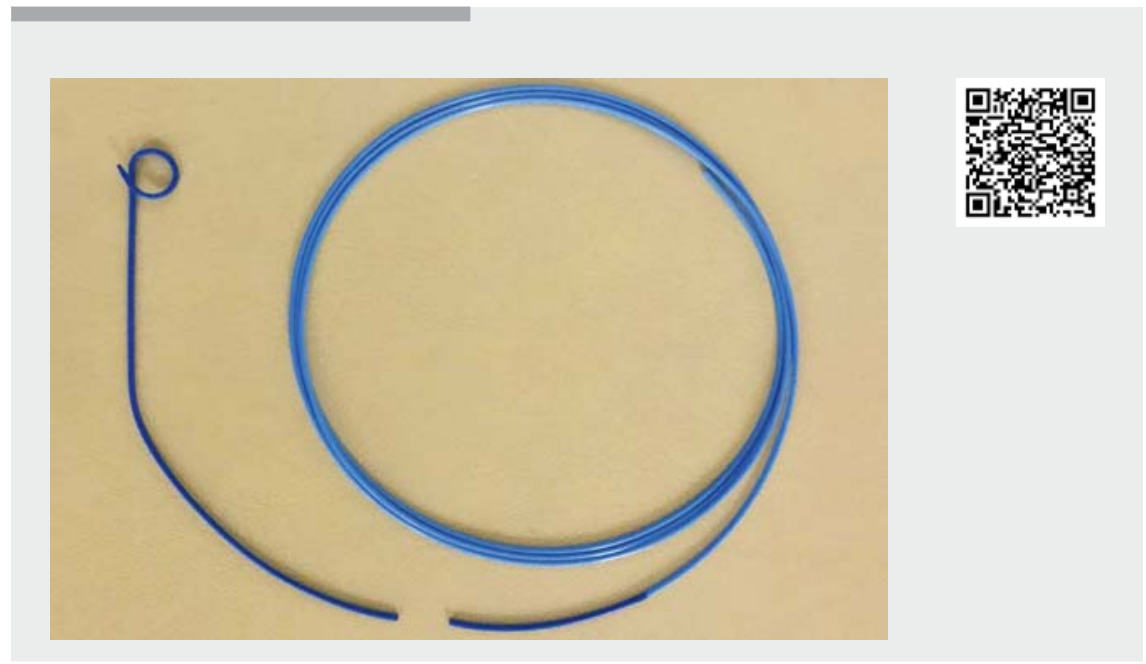

Video 1 Video showing re-intervention for endoscopic ultrasound-guided hepaticogastrostomy (EUS-HGS) using a plastic stent. The required length to place the tip in the stomach, as measured from the fluoroscopic image, was $25 \mathrm{~cm}$. A 7.5- $\mathrm{Fr}$ endoscopic nasobiliary drainage (ENBD) tube was cut to $25 \mathrm{~cm}$ and side holes were added to create a plastic stent of sufficient length. The long plastic stent was then successfully placed using the remaining ENBD tube as a pusher catheter. This novel concept of adjusting the length of a plastic stent according to the patient's anatomy so that it can be positioned properly may be a useful option in EUS-HGS.

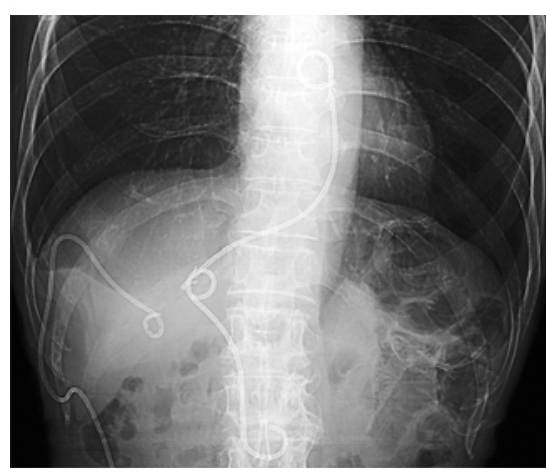

- Fig. 1 Radiographic image during endoscopic ultrasound-guided hepaticogastrostomy showing an 8-Fr single-pigtail plastic stent placed with the proximal tip in the esophagus after antegrade stenting had been performed with puncture from the esophagus as a puncture route was difficult to secure because of the postoperative anastomosis. The length of plastic stent was not sufficient to move the tip to the stomach.

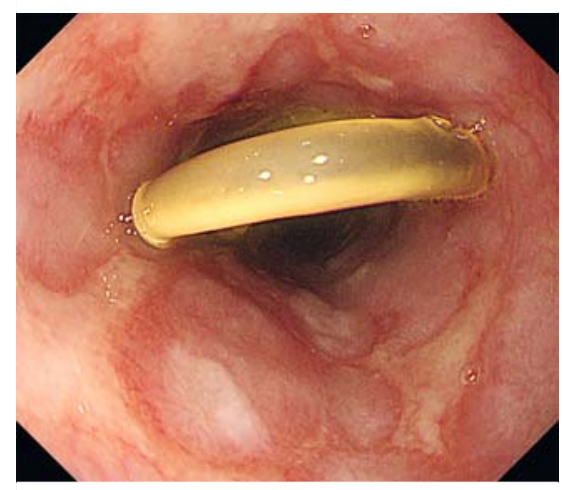

Fig. 2 Endoscopic image showing the tip of plastic stent in the esophagus, which had caused biliary esophagitis that required re-intervention. 


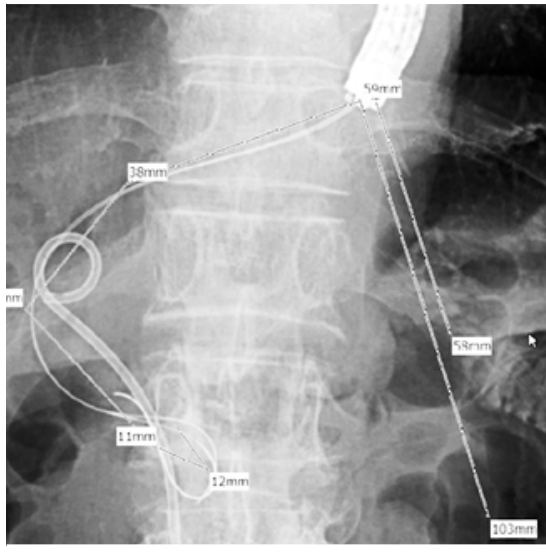

- Fig. 3 Fluoroscopic image showing that the required length to place the tip in the stomach was measured as being $25 \mathrm{~cm}$.

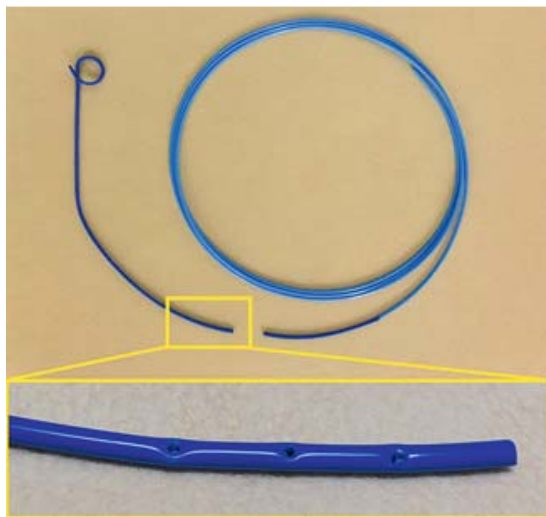

- Fig. 4 A 7.5-Fr endoscopic nasobiliary drainage tube was cut to $25 \mathrm{~cm}$ and side holes were added in order to create a plastic stent of sufficient length.

This novel concept of adjusting the length of a plastic stent according to the patient's anatomy so that it can be positioned properly may be a useful option in EUS-HGS ( Video 1). We consider that one of the reasons for selecting a plastic stent for EUS-HGS is because this method would not be possible with a metal stent.

Endoscopy_UCTN_Code_TTT_1AS_2AD

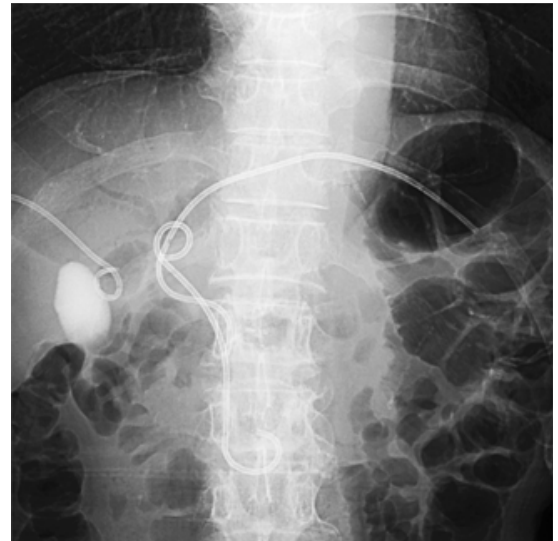

- Fig. 5 Radiographic image showing the long plastic stent, which was initially released into the esophagus using the remaining nasobiliary drainage tube as a pusher catheter and then guided into the stomach with grasping forceps, successfully positioned as planned.

\section{Competing interests}

None

The authors

Mamoru Takenaka, Kosuke Minaga, Tomoe Yoshikawa, Ayana Okamoto, Atsushi Nakai, Shunsuke Omoto, Masatoshi Kudo

Department of Gastroenterology and Hepatology, Kindai University Faculty of Medicine, Osaka-Sayama, Japan

\section{Corresponding author}

\section{Mamoru Takenaka, MD}

Department of Gastroenterology and Hepatology, Kindai University Faculty of Medicine, 377-2 Ohno-Higashi, Osaka-

Sayama, 589-8511, Japan

Fax: $+81-72-3672880$

mamoxyo45@gmail.com

\section{References}

[1] Ogura T, Nishioka N, Higuchi K. EUS-guided hepaticojejunostomy using novel plastic stent combined with antegrade metal stent placement. J Gastrointest Surg 2018; 22: 1309-1311

[2] Shiomi H, Masuda A, Kodama Y. Novel approach for successful endoscopic ultrasound-guided hepaticogastrostomy using a double-guidewire technique. Dig Endosc 2019; 31: e50 - e51

[3] Umeda J, Itoi T, Tsuchiya T et al. A newly designed plastic stent for EUS-guided hepaticogastrostomy: a prospective preliminary feasibility study (with videos). Gastrointest Endosc 2015; 82: 390 -396.e2

[4] Minaga K, Takenaka M, Miyata T et al. Through-the-mesh technique after endoscopic ultrasonography-guided hepaticogastrostomy: a novel re-intervention method. Endoscopy 2016; 48 (Suppl. 01): E369E370

[5] Minaga K, Takenaka M, Okamoto A et al. Reintervention for stent occlusion after endoscopic ultrasound-guided hepaticogastrostomy with novel use of a precut needleknife. Endoscopy 2018; 50: E153-E154

\section{Bibliography}

DOI https://doi.org/10.1055/a-0948-3630

Published online: 1.7.2019

Endoscopy 2019; 51: E362-E363

(c) Georg Thieme Verlag KG

Stuttgart · New York

ISSN 0013-726X

\section{ENDOSCOPY E-VIDEOS}

https://eref.thieme.de/e-videos

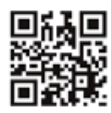

Endoscopy E-Videos is a free access online section, reporting on interesting cases and new

techniques in gastroenterological endoscopy. All papers include a high quality video and all contributions are freely accessible online.

This section has its own submission website at https://mc.manuscriptcentral.com/e-videos 